\title{
Reflexiones sobre nuestro objeto de estudio
}

Hoy quiero dedicar estas líneas a realizar una pequeña disertación de la comunicación, disciplina que atraviesa teórica y prácticamente todos los programas de la Facultad de Mercadeo, Comunicación y Artes, y que hoy en día se mueve dentro de sus referentes conceptuales y los cambios que se suceden con las tecnologías de la información y la comunicación.

Juntamente con los directores de departamentos y los docentes de planta y de cátedra de la Facultad, nos asiste la permanente inquietud acerca del ser, el deber ser, las competencias y los campos de formación y de trabajo de nuestros estudiantes, situación por la cual mantenemos un diálogo continuo sobre nuestro quehacer como compañeros actuantes de tales procesos de formación.

$\mathrm{Y}$ entonces nos vemos enfrentados a integrar diferentes ópticas del mismo objeto de estudio: 1) la de las teorías, los lenguajes, los medios y las mediaciones; 2) la de la relación entre la fundamentación, el análisis, la aplicación y la investigación, y 3) la de los campos y las tensiones entre el mundo de lo académico y el mundo laboral.

Según lo anterior, podemos decir que lo epistemológico surge como la necesidad de establecer un diferencial entre lo profesional y lo empírico que se mueve entre la apropiación inductiva o deductiva del objeto de estudio, y entre lo conductual y lo constructivista en la enseñanza de dicho objeto de estudio.

Entonces, empezamos a entender la necesidad de pasar del mundo de los significados, e incluso de las significaciones, al mundo de los sentidos; de entender que ya no nos centramos en los textos y los medios, sino en las convergencias y en 
las narrativas que recrean el mundo transdisciplinario y trasmediático.

Con esto último, entramos en el campo de las tecnologías; sin temor vemos que el mundo de la información deja de ser exclusivamente de los comunicadores y de los medios, y empieza a ganar terreno en la ingeniería, la psicología, la administración y la ciencia política, y no solo desde lo técnico para obtener información, generar bases de datos y establecer sistemas complejos de información, sino desde la capacidad del análisis de dicha información, es decir, desde los aportes cualitativos y cuantitativos para la toma de decisiones y de la búsqueda del bienestar colectivo.

Por lo tanto, las competencias no son ya las de los medios de comunicación, sino las de los sistemas de información y, con ello, la narrativa debe ir apropiando instancias de lo informativo, de las prácticas sociales significantes, de los imaginarios colectivos y de las interacciones liberadoras, entendidas estas últimas como la superación de la relación entre hegemonía y dependencia.

Lo anterior para volver al concepto de mediaciones que da valor a lo social en la comunicación, es decir, no al impacto de los mensajes, sino a los aspectos que, desde las interacciones humanas, se suceden y no pueden verse como simples paradigmas, sino como realidades mediadas por la apropiación y la pragmática.

En la fundamentación teórica, el principio de universalidad obliga a pensar en el tiempo y el espacio para asumir los principales autores y escuelas, sabiendo que la comunicación no se establece como una relación de opuestos, sino como una seguidilla de aportes al proceso, donde lo funcional, lo estructural y lo materialista histórico se suceden.

Así surge la posibilidad de no estudiar a los teóricos, sino las teorías, y cobran especial importancia los estudios del mensaje en cuanto texto, los del medio en cuanto vehículo para la transmisión de sentido y los de la interdisciplinaridad en cuanto posibilidad para la convergencia.

En el análisis, el ejercicio desborda los estudios cualitativos y cuantitativos y establece categorías más ontológicas sobre la comunicación como objeto de estudio y sobre la valoración de lo social como producto de la interacción. Surge el aporte de Zuleta sobre el elogio de la dificultad vista no como lo difícil, sino como lo elaborado y lo 
complejo, es decir, la comunicación que evita el camino fácil de lo inmediato y del juicio de valor y trasciende al terreno de lo social y de las apropiaciones culturales.

En este sentido, la aplicación se vuelve el gran tema de estudio, y no para regresar a los puntos fáciles de los medios de comunicación, de las técnicas que sugirieran la existencia de fórmulas para aprender y de la mimetización entre comunicación y periodismo. Con los avances tecnológicos, el emisor recupera el papel como comunicador, es decir, el actuante de un proceso complejo en el que las relaciones humanas y sociales se establecen como apropiación de lenguajes, espacios, formas culturales y niveles de significación.

Por lo tanto, el comunicador periodista da cuenta de la realidad con mayor capacidad de contrastar sus fuentes y referentes, el profesional audiovisual aprovecha los nuevos canales para fragmentar, complementar, profundizar, ampliar y extender el mismo discurso en la variedad de los soportes; en medio de tanta pantalla, el profesional de las artes de la escena recupera el espacio del cara a cara, de lo corporal, de la voz y del movimiento, para generar otros espacios liberadores.
Más allá del artista que crea y recrea sus realidades, el comunicador se convierte en el facilitador de las expresiones de sus pares sociales para controvertir o fortalecer, para cuestionar o afirmar, para protestar o para liberar todas sus realidades.

Según lo anterior, la investigación ya no es un estado ulterior del conocimiento, sino el producto de conocimiento mismo; los observatorios de medios pasan de ser espacios descriptivos de las comunicaciones e interacciones humanas, para convertirse en los referentes que narran en tiempo presente lo que acontece.

Así la imagen recobra importancia, más allá de su discurso ideológico o artístico, se convierte en otra forma de contar la realidad desde el supuesto de que sus destinatarios son más multimediales. $\mathrm{Y}$ aparecen las preguntas de la comunicación en cuanto posibilidad humana de construir sentido y otros estudios, más pragmáticos, como aquel que cuestiona si a la televisión le pasará lo mismo que al teléfono familiar, que desaparece lentamente, mientras se establecen otras prácticas significantes y otras formas de producción.

Finalmente, aunque somos conscientes de que la universidad debe estar para el mundo de lo 
posible, es decir, de lo innovador, lo transformador y lo liberador, y no para el mundo de lo real, es decir, para como está establecido el statu quo, siempre debemos pensar cuáles son aquellos campos en los que se desempeñará el egresado, que más allá de cargos, funciones, organizaciones y empresas, nos habla otra vez de los espacios de los medios, del periodismo, de las organizaciones, pero también de lo público, de la gestión social, de la llamada industria cultural y de lo alternativo en los medios.

Este marco de referencia nos habla un poco de cómo pensamos la educación desde nuestros programas académicos, de cómo establecemos procesos articuladores para toda la cadena de formación universitaria, de qué nos ocupa cuando tomamos decisiones en las renovaciones de los planes de estudio, de cuáles son los diferenciales que establecemos cuando queremos tener un programa y unos egresados de calidad.

Aquí simplemente rasgo unas líneas, pero la invitación para los docentes es a promover más espacios que hablen de los programas y de sus objetos de estudio; llévenlos al terreno de las narrativas, asegúrense de que cada día al terminar la clase haya valido la pena haber asistido; y para los estudiantes, que más allá de encontrar fórmulas detrás de los flujogramas, los leads y las convenciones técnicas, es para que aprovechen lo que de comunicadores tienen sus docentes, que se dejen provocar de sus experiencias, de sus lecturas, de sus escritos y de sus realizaciones.

Sergio Hernández Muñoz

Decano Facultad de Mercadeo, Comunicación y Artes 